\title{
Uma Avaliação de Modelos de Cadeias Logísticas da Entrega de Jornais a Assinantes e Coleta de Leite a Granel
}

\section{An Evaluation of Two Supply Chain Models for the Newspapers Subscribers Delivery and Bulk Milk Collection}

\author{
Marcos José Negreiros Gomes \\ UNIVERSIDADE ESTADUAL DO CEARÁ \\ Mestrado Profissional em Computação - UECE/CEFET \\ Av. Paranjana, 1700 - Campus do Itaperi \\ Fortaleza - Ceará - CEP: 60740-000 \\ e-mail: negreiro@uece.br \\ Augusto Wagner de Castro Palhano \\ UNIVERSIDADE ESTADUAL DO CEARÁ \\ Mestrado Profissional em Computação - UECE/CEFET \\ Av. Paranjana, 1700 - Campus do Itaperi \\ Fortaleza - Ceará - CEP: 60740-000 \\ e-mail: augustopalhano@graphvs.com.br \\ Irauê Casarin Vieira da Silva \\ UNIVERSIDADE ESTADUAL DO CEARÁ \\ Mestrado Profissional em Computação - UECE/CEFET \\ Av. Paranjana, 1700 - Campus do Itaperi \\ Fortaleza - Ceará - CEP: 60740-000 \\ e-mail: natrib@terra.com.br
}

\begin{abstract}
RESUMO
Este trabalho apresenta uma avaliação de duas alternativas logísticas - Agrupamento e Roteamento Generalizado $\times$ Localização em Centro e Roteamento, em duas unidades de negócios distintas: Distribuição de Jornais a Assinantes e Coleta de Leite a Granel. Descrevemos com detalhes as aplicações e suas particularidades, assim como apresentamos os resultados de nossas análises comparativas, usando os modelos sob os mesmos dados dos contextos de análise. Foi utilizada a ferramenta SisRot News, que implementa os modelos logísticos aqui discutidos para estas cadeias de suprimentos.
\end{abstract}

Palavras Chaves: Cadeias de Suprimento, Localização e Roteamento, Agrupamento, Metaheurísticas. 


\begin{abstract}
This work shows an evaluation of two supply chain network models - resulting from Clustering and Generalized Routing $\times$ Center Location and Routing, in two distinct business units: Newspaper distribution to subscribers and bulk milk collection. We proceed a detailed description of the application and their peculiarities, and we present results of our analysis, using these network models over the same data set. We used for the purpose of this work the SisRot News software tool, which implements the logistics network models for these supply chains.
\end{abstract}

Keywords: Supply-Chain, Location-Routing, Clustering, Metaheuristics .

\title{
1. Introdução
}

A configuração da rede logística pode envolver aspectos relacionados com a localização da planta, do depósito e do varejista. As decisões estratégicas que têm efeitos de longo prazo sobre as empresas são, Sanchi-Levi et al 2003:

i) determinação do número apropriado de depósitos,

ii) determinação da localização de cada depósito,

iii) determinação do tamanho de cada depósito,

iv) alocação dos produtos em cada depósito e

v) determinação de quais produtos os clientes receberão de cada depósito.

Normalmente, este contexto de definição se apóia em situações de suprimento já herdadas pelas companhias ao longo dos anos, haja vista a visão empreendedora de seus gestores, e o modo como sempre imaginam chegar ao cliente da forma mais barata. Além disto, considera-se também que ainda hoje os recursos de projeto de cadeias logísticas não são uma realidade, pois se trata de um instrumento computacional caro e de difícil acesso, mais ligado à simulação, e que dificilmente integra os recursos da otimização para esta etapa de planejamento. Alguns softwares, como o TransCAD e CAPS Logistics, podem fazer isto de forma não integrada e sem alguns dos recursos algoritmos pertinentes, o que dificulta na tomada da decisão, (http://www.caliper.com/tcovu.htm), http://www.ssaglobal.com/solutions/scm/index.aspx $)$.

O objeto principal deste trabalho é a avaliação da rede logística de distribuição de jornais a assinantes do Jornal O GLOBO (JG) do Rio de Janeiro, projeto piloto coordenado pela Graphvs e Multistrata, assim como conhecer a logística de distribuição de um jornal cearense, o Jornal O POVO (JP). Para se obter uma medida de desempenho entre as duas cadeias logísticas, estudamos suas variações e potencialidades de aplicação real, que através de estudos realizados sobre métodos de agrupamento e roteirização (Problema Generalizado de Percurso de Veículos - PGPV) e outro de Localização e Roteamento, Negreiros \& Palhano (2004b), Laporte (1988), chegamos a uma ferramenta integrada capaz de avaliar o projeto de 
redes logísticas de suprimento, que integra os conceitos de simulação e otimização

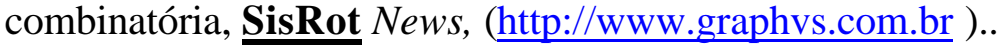

Dentro deste contexto, para avaliar melhor a robustez e generalidade da solução do primeiro caso, também incluímos neste estudo uma verificação do problema de seleção da estrutura logística para a Coleta de Leite a Granel, uma alternativa logística de coleta de leite que vem se disseminando no Brasil desde 1995, e que apesar de ter custos reduzidos, imputam ao produtor custos com estrutura de resfriamento que é onerosa, da Silva (2000).

A seguir discutimos na seção 2 as definições das cadeias logísticas para suprimento de jornais a assinantes, na seção 3 comparamos os resultados computacionais dos dois casos e indicamos o modelo de cadeia mais adequado, e na seção 4 introduzimos uma visualização da estrutura da cadeia do leite a granel, avaliamos o modelo logístico mais adequado neste caso, para um estudo de caso realizado com dados da Bacia Leiteira de Bom Sucesso/MG.

\section{Definição das Redes de Suprimento de Jornais a Assinantes}

A rede logística do jornal O GLOBO, constitui-se de uma base de produção centralizada (BP) e onze centros de distribuição e montagem (CD) dispersos em pontos estratégicos pela cidade, além de milhares de entregas diárias. Centenas de veículos e entregadores saem dos CDs para fazer a distribuição dos jornais. Os veículos levam, além dos jornais, os entregadores, carrinhos de distribuição e os jornais. Desta forma o espaço disponível para os jornais fica reduzido nas Kombis. Na medida em que os cadernos (módulos separados dos jornais) vão sendo terminados na BP, os mesmos são enviados para os CDs onde é feita a composição final do jornal pelos próprios entregadores. Cada veículo transporta os jornais e o pessoal de despacho, deixando-os em locais (de entrega) específicos para dali serem entregues pelos despachantes (em média levam 50 jornais) para um conjunto de clientes determinados (que podem receber de 1-10 jornais). Consideramos apenas a logística de distribuição a partir dos centros de distribuição, figuras 1 e 2.

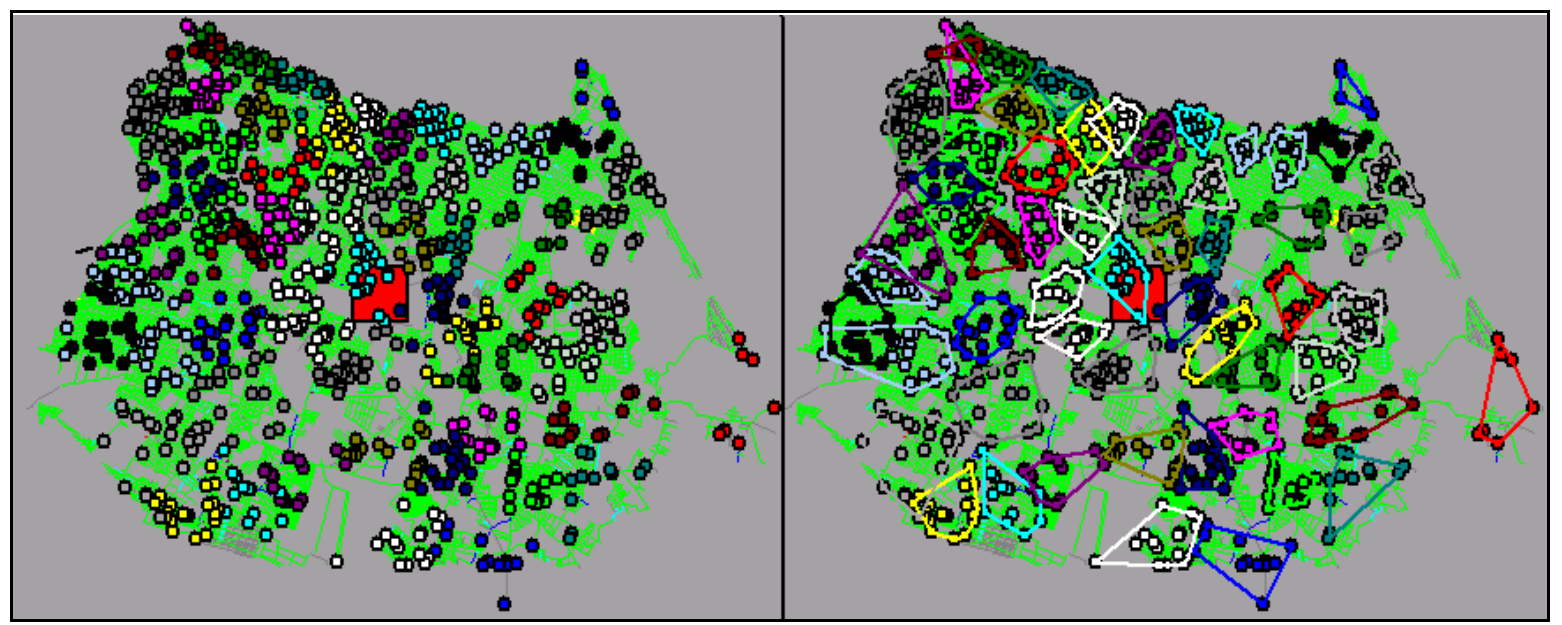

Figura 1: Disposição inicial das entregas e formação dos grupos. 

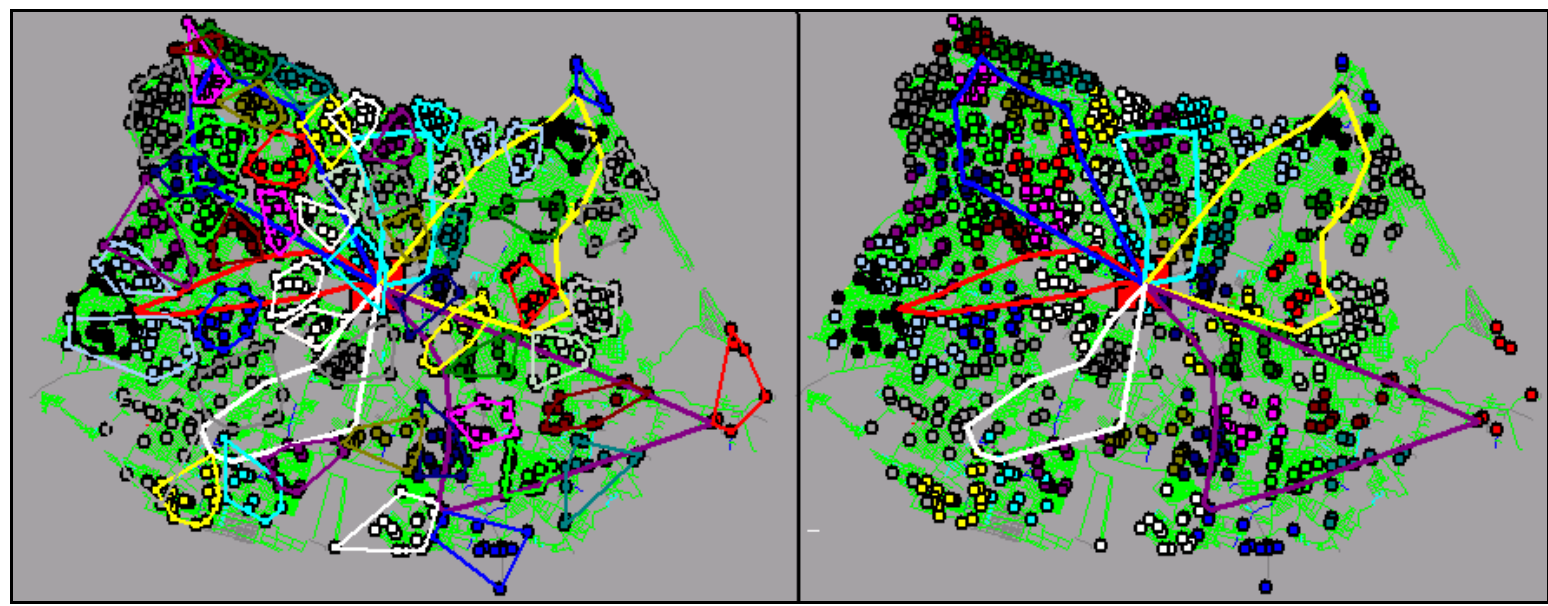

Figura 2: Visão das Rotas dos veículos com os grupos de entregas e solução final das rotas de distribuição.

Para resolver a logística do jornal O GLOBO, utilizamos a técnica de dividir para conquistar. Determinamos quais os clientes que serão atendidos por cada Centro de Distribuição (CD), usando o critério da distância euclidiana. Em seguida consideramos a logística de todos os CDs separadamente, conforme Palhano (2004).

A rede logística do jornal O POVO é descrita do seguinte modo: A base de produção do jornal e o centro de distribuição situam-se na mesma unidade. Os veículos já saem com jornais totalmente montados. É utilizado um pequeno número de veículos (com capacidade de 2200 jornais aproximadamente) que partem da base e levam os jornais a pontos avançados estratégicos (PA) pré-determinados que se encontram dispersos na cidade. Os jornaleiros se concentram nestes PAs de onde partem para fazer a entrega dos jornais aos assinantes.

Os dados atuais desta logística foram conseguidos em entrevista com o Sr. Demócrito Filho, diretor do Jornal O POVO, no dia 24/08/2004. Os principais aspectos estão listados abaixo:

- custo fixo geral por veículo: 2.5 salários mínimos (sm) mensais;

- capacidade de transporte dos veículos: 2000 a 2200 jornais;

- custo do jornaleiro: 0.65 a $0.70(\mathrm{sm})$ e um adicional de 0.05 (sm) se não houver reclamação das entregas;

- existe um coordenador para cada área de entrega que trabalha com equipes de 15 a 20 jornaleiros, tendo 1 ou 2 reservas, e os distribui segundo sua própria lógica;

- cada jornaleiro também poderá entregar nas bancas de revistas que estejam na sua área de cobertura;

- as entregas diárias variam de 13 a 14 mil unidades durante a semana e de 23 a 24 mil nos finais de semana;

- as bancas recebem aproximadamente 3000 jornais diários durante a semana e por volta de 5000 nos finais de semana;

- os pontos avançados estratégicos (pas) não têm custo de instalação ou mesmo qualquer custo associado ao seu posicionamento, uma vez que é intinerante, e apenas considerado como um "local de encontro".

As figuras 3 a 6 detalham esta configuração de suprimento do Jornal O Povo. 
Os jornaleiros geralmente utilizam bicicletas, motos, ou fazem o percurso a pé, dependendo da dispersão espacial de cada grupo de assinantes contidos em cada conjunto de entregas respectivo.

Normalmente, os pontos avançados são fixos e determinados previamente de acordo com a disposição geográfica das entregas. Nossa abordagem, implementada no sistema SisRot News, foi um pouco diferente, ou seja, o conjunto de PAs é criado dinamicamente na fase de agrupamento das entregas. Isto sugere uma visão mais interessante em termos da aplicação diversificada de entregas, ou seja, o Jornal poderá ter clientes com assinatura diferenciada, por exemplo: somente segunda-feira, quarta-feira e sexta-feira; ou quaisquer combinações de dias. Isso poderia diminuir o custo da assinatura, daria aos clientes mais opões, e o Jornal teria uma atuação mais dinâmica e competitiva no mercado local.

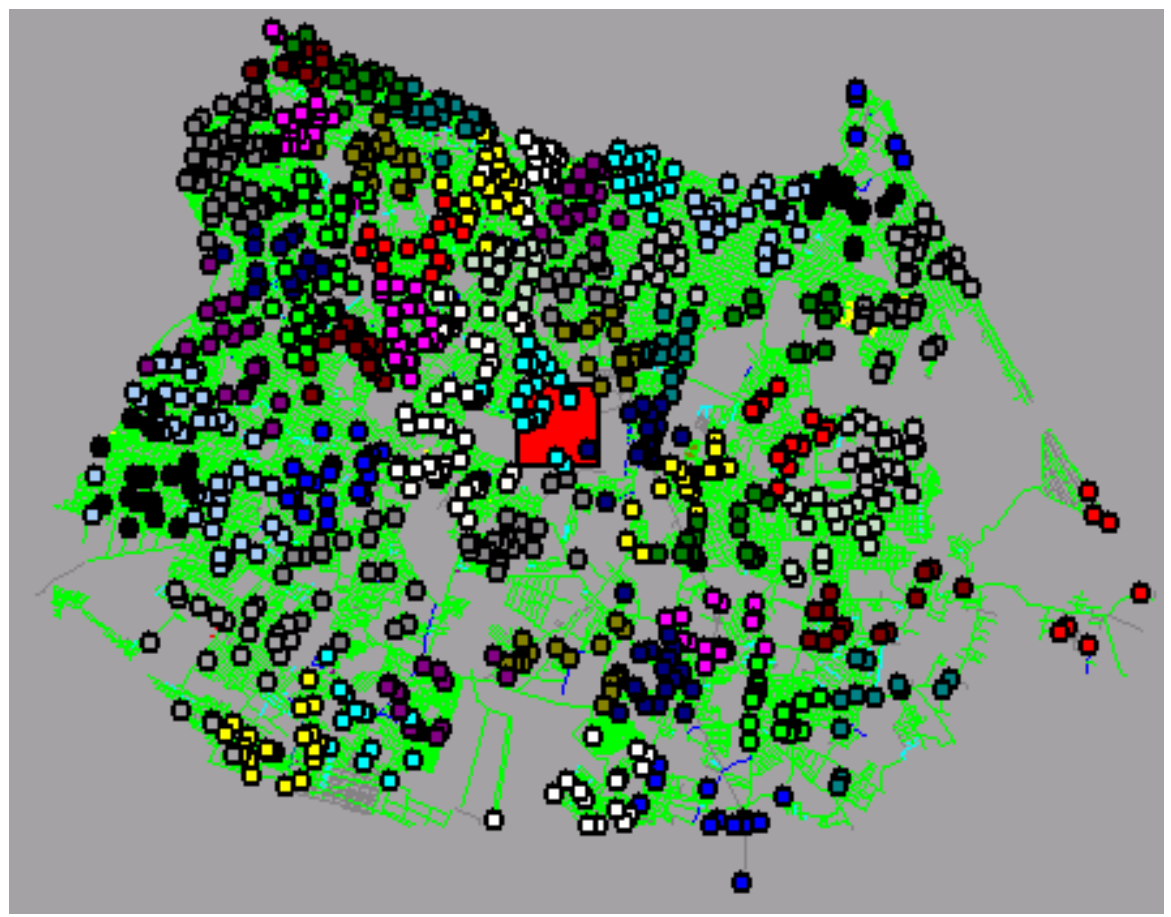

Figura 3: Visão da Base de Operação (retângulo) e os conjuntos de entregas (círculos) de um dia. 


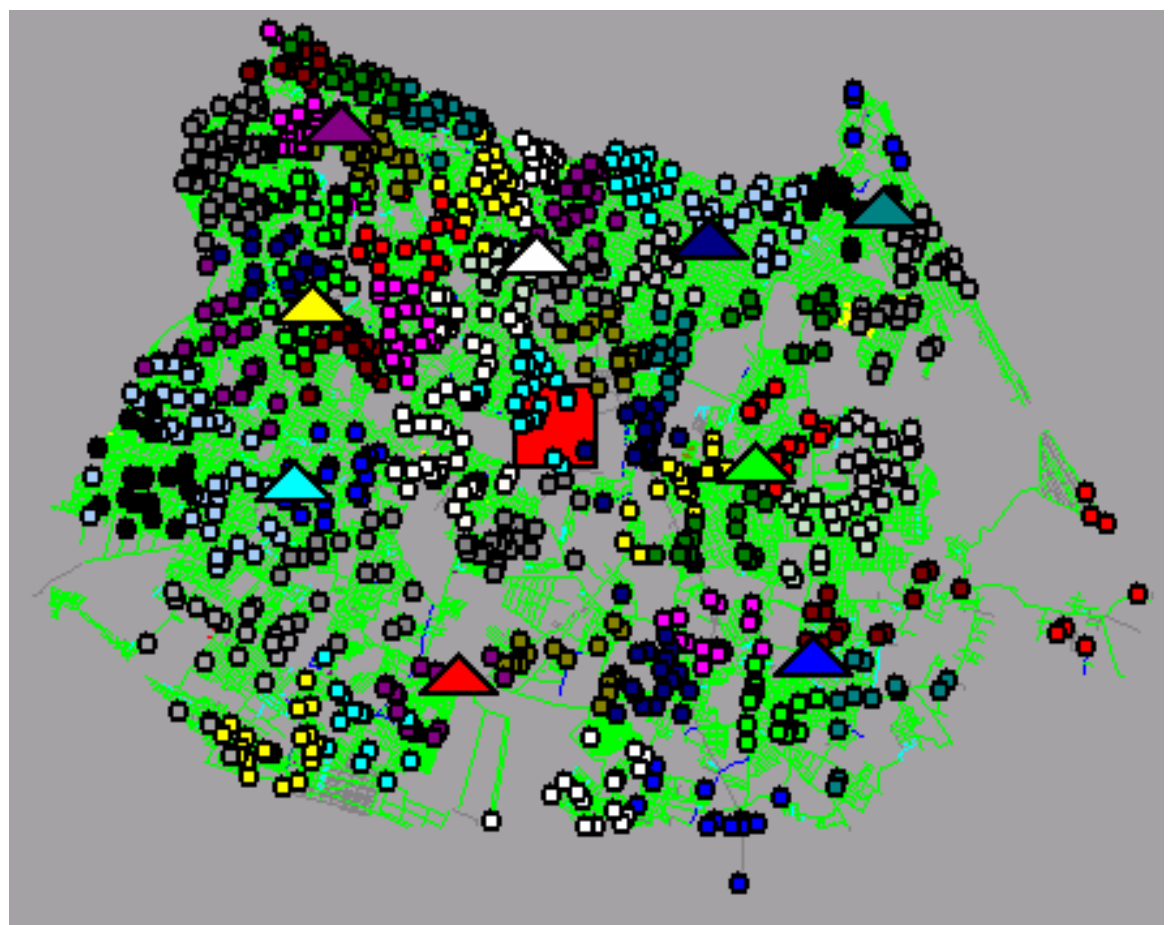

Figura 4: Visão dos pontos avançados (triângulos).

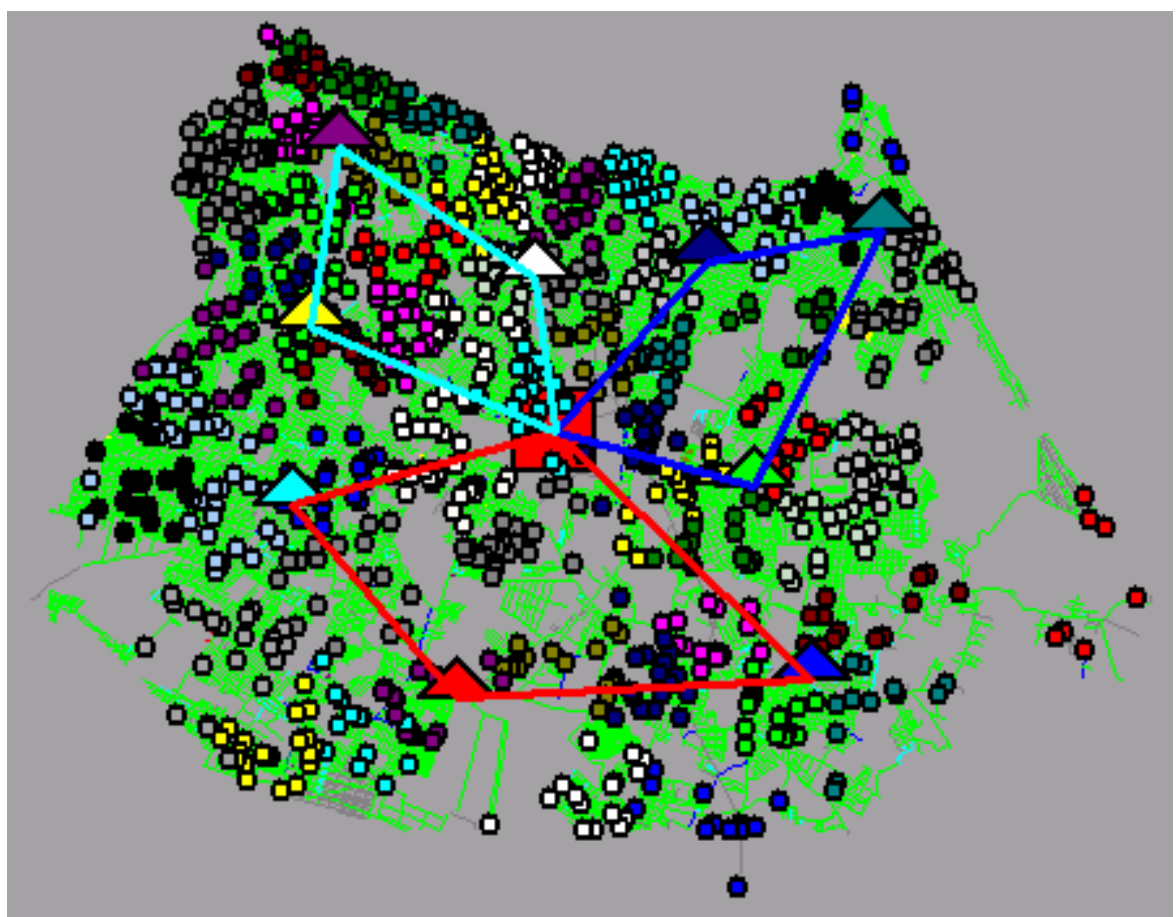

Figura 5: Rotas dos veículos de distribuição da Base para os pontos avançados. 


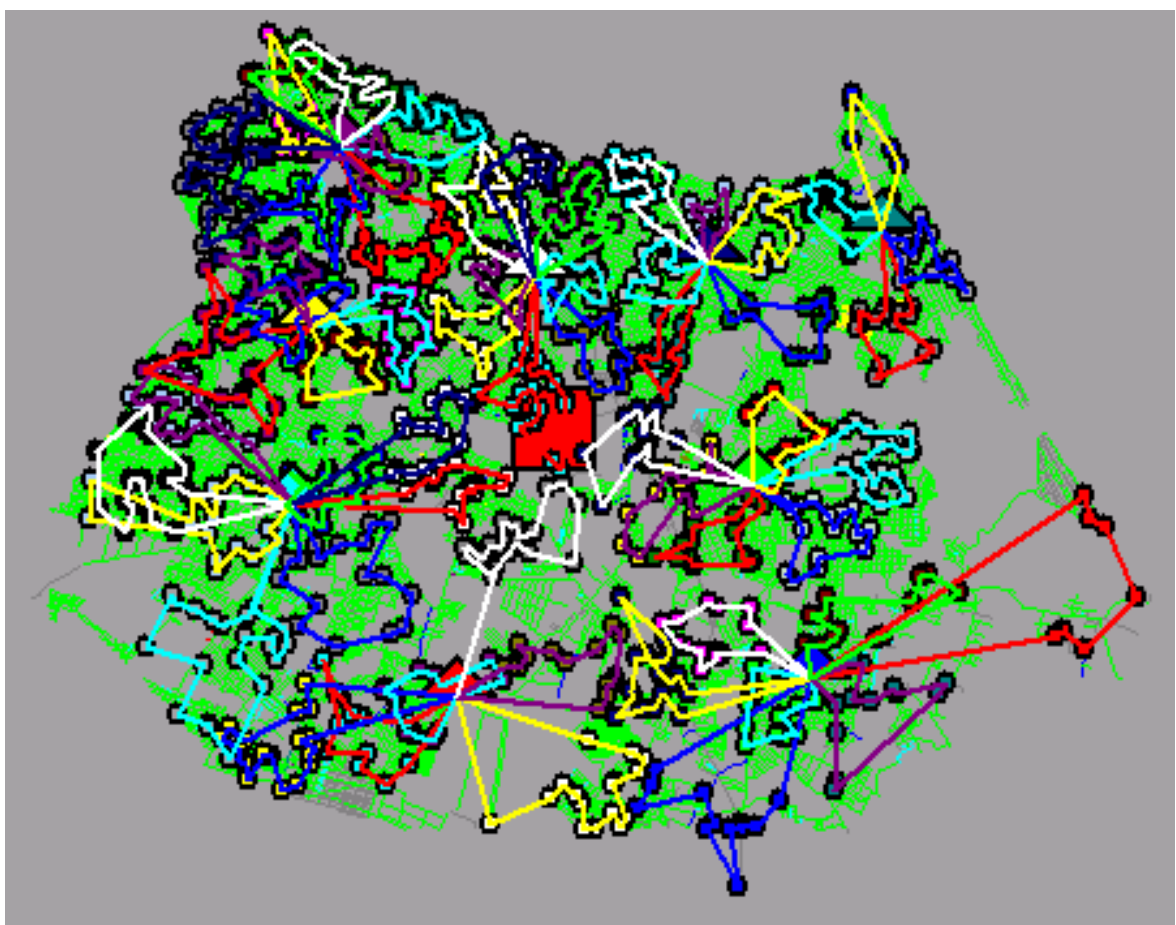

Figura 6: Rotas dos jornaleiros saindo dos pontos avançados.

\section{Comparativo entre as Redes de Suprimento para Entrega de Jornais}

Nossas instâncias foram geradas de forma aleatória e estão uniformemente distribuídas na malha viária da cidade de Fortaleza/CE. O uso desta distribuição pode influenciar para que os grupos sejam homogêneos em todos os pontos da cidade. Porém, nossos pontos de entrega foram gerados a partir das esquinas da cidade, assim conseguimos gerar amostras que são mais concentradas em áreas de concentração populacional e mais dispersas naquelas de pouca população.

Para podermos fazer comparações adequadas entre as duas estratégias, consideramos as instâncias de Palhano (2004), porém com um único centro de distribuição (CD). Avaliamos então a diferença entre as rotas do esquema do Jornal O GLOBO, ou seja, as rotas dos veículos saem do $\mathrm{CD}$, passam pelos grupos, sendo escolhida uma entrega de cada grupo como ponto de despacho e, finalmente, retornam ao CD.

Segundo a abordagem do jornal O POVO, os veículos partem do CD e distribuem os jornais para os pontos avançados de onde se concentram os jornaleiros. Os pontos avançados têm um limite de jornaleiros que cobrem uma determinada região. Os jornaleiros fazem um percurso de despacho e depois retornam ao CD. Para este caso, tivemos que agrupar clientes e em seguida agrupar centros de grupos de clientes, e verificar percursos passando por estes centros com as restrições de capacidade (500 jornais por Kombi) e temporais (2h) para os veículos, Palhano (2004). 
Para facilitar nossa comparação entre as duas estratégias, escolhemos o método Estático do PGPV, dentre os descritos por Negreiros \& Palhano (2004b) e dois métodos em relação à nova abordagem proposta pelo Jornal O POVO, descrita na seção anterior. Nesta abordagem, utilizamos uma etapa do tipo Rotear Primeiro e Agrupar Depois (RPAD) com uma fase de aleatorização tipo Monte Carlo, e o outro método sendo de varreduras (Sweep) todos com VNS na fase de refinamento da solução, Beasley (1983), Gillet \& Miller (1974), Hansen \& Mladnovic (2000), Bodin et al (1983).

Nesse segundo método, fizemos uma variação na técnica de agrupamento, ou seja, agrupamos todas as entregas de cada ponto avançado, considerando a capacidade de cobertura de assinantes respectiva e, a partição das rotas, segundo a capacidade de entrega do jornaleiro (fixada em 50 para ambas as estratégias), foi feita através do procedimento Sweep. Observe a menor quantidade de grupos formados, figura 7.

A estratégia do O GLOBO utiliza um número maior de veículos devido à capacidade de transporte de jornais ser menor, isto é, transportam tanto entregadores quanto jornais. Considerando o custo global (rotas dos veículos e rotas dos jornaleiros), o método do $\mathrm{O}$ GLOBO possui menor valor do que o método do jornal O POVO para todas as instâncias testadas. Contudo, as rotas dos veículos são sempre menores na estratégia do O POVO, deixando um maior esforço para as rotas dos jornaleiros, que na verdade possuem custo reduzido porque a grande maioria utiliza bicicletas, veículos de baixo consumo de combustível (motos), ou ainda fazem o percurso a pé em áreas de grande concentração de entregas. As distâncias totais podem ser vistas na tabela 1. A coluna "Entregas" se refere ao número total de entregas diárias, a coluna denominada "Jornais" contém o número de jornais distribuídos, as demais colunas registram as distâncias totais percorridas pelos veículos e jornaleiros segundo as duas estratégias abordadas.

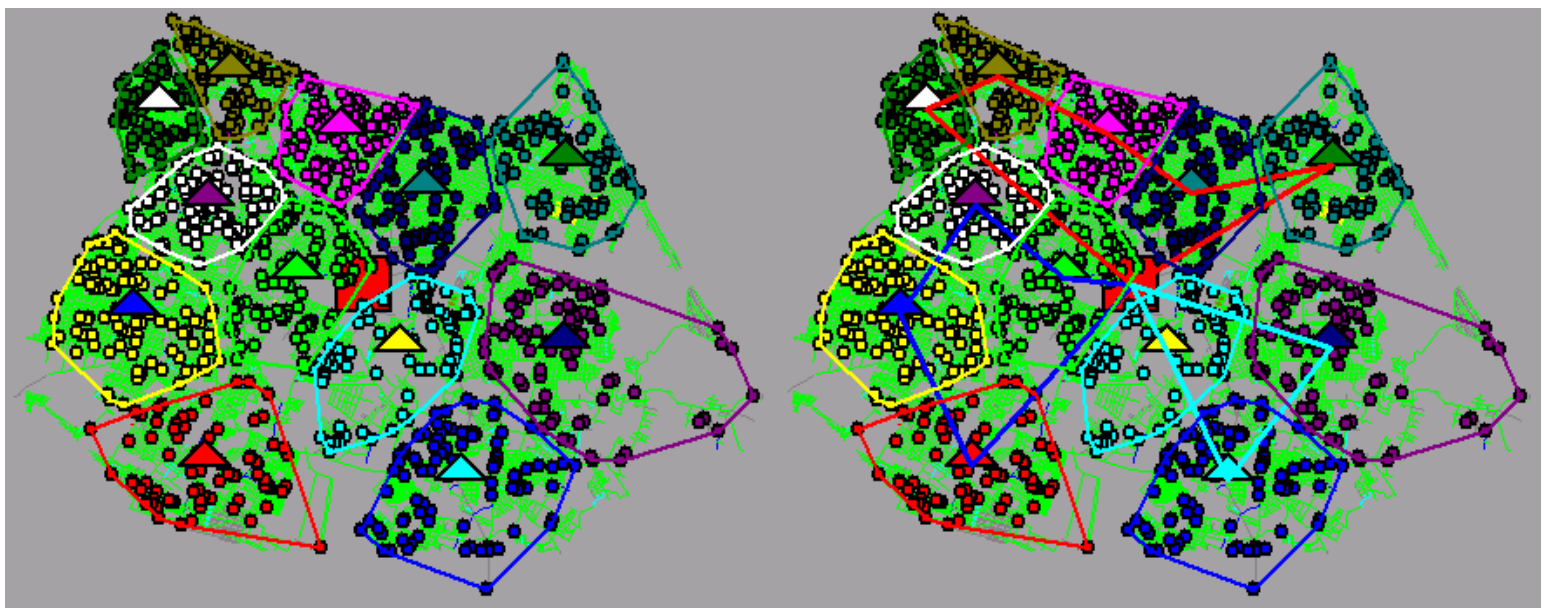

Figura 7: Estratégia do Jornal O POVO utilizando o método Sweep.

Tabela 1: Resultados das distâncias totais (veíc + ent) realizadas pelos dois métodos.

\begin{tabular}{|c|c|r|r|r|}
\hline \multicolumn{2}{|l}{ Distâncias totais das rotas em Km } \\
\hline \multirow{2}{*}{ Entregas } & \multirow{2}{*}{ Jornais } & \multicolumn{1}{c|}{ O GLOBO } & \multicolumn{2}{|c|}{ O POVO } \\
\cline { 3 - 5 } & & Método Estático & \multicolumn{1}{c|}{ RPAD } & SWEEP \\
\hline 1000 & 5580 & 644,84 & 783,99 & 887,92 \\
5000 & 27544 & 1807,92 & 1798,84 & 2167,85 \\
10000 & 55077 & 2935,94 & 2594,71 & 3647,99 \\
15000 & 81994 & 3974,26 & 3271,93 & 5048,87 \\
\hline
\end{tabular}


Dois fatores fazem com que o custo global das rotas dos veículos de distribuição (jornal O POVO) seja menor: O primeiro se caracteriza pela maior capacidade de carga, já que os carros somente transportam jornais, e isso diminui a quantidade de veículos necessários para transportar uma mesma carga de jornais. O segundo fator se refere à disposição dos PAs. Os pontos avançados localizam-se no centro geométrico de alguns grupos de entrega mais próximos, fazendo com que os veículos realizem percursos em uma área mais centralizada, evitando o percurso até os grupos periféricos. A disposição geográfica desta observação pode ser vista na fig 5 e os resultados numéricos na tabela 2.

Tabela 2: Totais das distâncias realizadas pelos veículos de distribuição.

\begin{tabular}{|c|c|r|r|r|}
\hline \multicolumn{2}{|c|}{ Distâncias das rotas dos veículos em Km } \\
\hline \multirow{2}{*}{ Entregas } & \multirow{2}{*}{ Jornais } & \multicolumn{1}{|c|}{ O GLOBO } & \multicolumn{2}{|c|}{ O POVO } \\
\cline { 3 - 5 } & & Método Estático & \multicolumn{1}{c|}{ RPAD } & SWEEP \\
\hline 1000 & 5580 & 226,21 & 76,68 & 74,31 \\
5000 & 27544 & 864,21 & 265,16 & 260,45 \\
10000 & 55077 & 1630,83 & 462,88 & 498,57 \\
15000 & 81994 & 2345,17 & 663,09 & 723,90 \\
\hline
\end{tabular}

Em relação à distância percorrida pelos jornaleiros (entregadores), o método do Jornal O GLOBO é mais eficiente, pois os jornaleiros já iniciam em um ponto do seu roteiro (algum assinante), ou seja, não existe percurso entre o centro de distribuição e a primeira entrega e o retorno da última entrega para o $\mathrm{CD}$. A diferença percentual entre os métodos do Jornal $\mathrm{O}$ GLOBO e o do Jornal O POVO (RPAD) é de 60\% aproximadamente. Considerando que o número de entregadores se manteve praticamente o mesmo entre os métodos. Isto é um reflexo do método de agrupamento proposto por Negreiros \& Palhano (2004a) e também do caixeiro viajante que foi o procedimento usado no cálculo das rotas dos entregadores, tabelas 3. e 5. Uma pequena variação do número de entregadores (grupos) ocorre quando utilizamos o procedimento Sweep para separar as rotas de entrega, o qual obteve melhor performance somente na menor instância de 1000 entregas. Este detalhe nos indica que, para instâncias grandes, é melhor utilizar um método de agrupamento e depois roteirizar os elementos dos grupos. Além de gerar menor número de rotas, também é calculado mais rapidamente, haja vista a complexidade do método Sweep ser mais elevada.

Tabela 3: Distâncias das rotas dos jornaleiros.

\begin{tabular}{|c|c|r|r|r|}
\hline \multicolumn{2}{|c|}{ Distâncias das rotas dos entregadores em Km } \\
\hline \multirow{2}{*}{ Entregas } & \multirow{2}{*}{ Jornais } & \multicolumn{1}{c|}{ O GLOBO } & \multicolumn{2}{|c|}{ O POVO } \\
\cline { 3 - 5 } & & Método Estático & \multicolumn{1}{|c|}{ RPAD } & SWEEP \\
\hline 1000 & 5580 & 418,63 & 707,31 & 813,61 \\
5000 & 27544 & 943,71 & 1533,68 & 1907,40 \\
10000 & 55077 & 1305,11 & 2131,83 & 3149,42 \\
15000 & 81994 & 1629,09 & 2608,84 & 4324,97 \\
\hline
\end{tabular}

Todas as metodologias testadas fornecem como resultado: o dimensionamento da frota de distribuição - número de veículos, as rotas de distribuição; o número de entregadores necessário para o despacho total de jornais diariamente, as rotas de entrega dos jornaleiros e, também, o tipo mais adequado de veículo que cada jornaleiro deverá utilizar. Contudo, para obter este último dado, necessitaríamos avaliar a relação entre a dispersão do grupo de entre gas e o tipo de veículo capaz de realizar a rota no tempo máximo estabelecido ( $2 \mathrm{~h}$ ). 
Tabela 4: Número total de veículos necessário.

\begin{tabular}{|c|c|c|c|c|}
\hline \multicolumn{2}{|c|}{ Número de rotas dos veículos } \\
\hline \multirow{2}{*}{ Entregas } & \multirow{2}{*}{ Jornais } & O GLOBO & \multicolumn{2}{c|}{ O POVO } \\
\cline { 3 - 5 } & & Método Estático & RPAD & SWEEP \\
\hline 1000 & 5580 & 12 & 3 & 3 \\
5000 & 27544 & 57 & 15 & 14 \\
10000 & 55077 & 113 & 29 & 28 \\
15000 & 81994 & 169 & 42 & 42 \\
\hline
\end{tabular}

Tabela 5: Número total de entregadores necessário.

\begin{tabular}{|c|c|c|c|c|}
\hline \multicolumn{2}{|l|}{ Número de rotas dos entregadores } \\
\hline \multirow{2}{*}{ Entregas } & \multirow{2}{*}{ Jornais } & O GLOBO & \multicolumn{2}{c|}{ O POVO } \\
\cline { 3 - 5 } & & Método Estático & RPAD & SWEEP \\
\hline 1000 & 5580 & 119 & 119 & 118 \\
5000 & 27544 & 577 & 577 & 580 \\
10000 & 55077 & 1151 & 1151 & 1159 \\
15000 & 81994 & 1700 & 1700 & 1722 \\
\hline
\end{tabular}

Dentro desse contexto, nota-se nas tabelas 4 e 5 . o alto custo fixo e variável associado à solução do Jornal O GLOBO que sempre supera a solução do Jornal O POVO. O preço disto é o aumento nas distâncias percorridas pelos entregadores que, conforme podemos ver na tabela 6 , há uma diferença considerável entre as soluções, fazendo com que a solução do Jornal O GLOBO seja a mais adequada nesta fase.

Se considerarmos a solução do Jornal O POVO, neste caso, o trabalho dos entregadores na periferia fica comprometido, pois o jornal local precisaria também investir em veículos motorizados (motos) para vencer a dispersão dos assinantes na entrega. Além disto, as condições do tempo e adversidades podem criar infortúnios naturais que são específicos da aplicação, uma vez que as turmas devem estar dispostas nos pontos avançados (PAs).

Tabela 6: Deslocamentos médios dos entregadores conforme a solução

\begin{tabular}{|c|c|c|c|c|}
\hline \multicolumn{3}{|c|}{ Média de Deslocamento das Rotas dos Entregadores em Km } \\
\hline \multirow{2}{*}{ Entregas } & \multirow{2}{*}{ Jornais } & O GLOBO & \multicolumn{2}{|c|}{ O POVO } \\
\cline { 3 - 5 } & & Método Estático & RPAD & SWEEP \\
\hline 1000 & 5580 & 3,518 & 5,944 & 6,895 \\
5000 & 27544 & 1,636 & 2,658 & 3,289 \\
\cline { 3 - 5 } 10000 & 55077 & 1,134 & 1,852 & 2,717 \\
15000 & 81994 & 0,958 & 1,535 & 2,512 \\
\cline { 3 - 5 }
\end{tabular}


Tabela 7: Diferenças operacionais (uso de veículos) - Custo Operacional da Entrega $(\mathrm{COE})=$ $\mathrm{CF} \times \mathrm{NV}$ (unidade: salários mínimos)

\begin{tabular}{|c|c|c|r|r|}
\hline \multirow{2}{*}{ Entregas } & \multirow{2}{*}{ Jornais } & O GLOBO & \multicolumn{2}{|c|}{ O POVO } \\
\cline { 3 - 5 } & & $\begin{array}{c}\text { Método } \\
\text { Estático } \\
\text { COE }\end{array}$ & \multirow{2}{*}{$\begin{array}{c}\text { RPAD } \\
\text { COE }\end{array}$} & \multicolumn{1}{c|}{ SWEEP } \\
\cline { 5 - 5 } & & \multicolumn{1}{c|}{ COE } \\
\hline 1000 & 5580 & 30,00 & 7,50 & 7,50 \\
5000 & 27544 & 142,50 & 37,50 & 35,00 \\
10000 & 55077 & 282,50 & 72,50 & 70,00 \\
15000 & 81994 & 422,50 & 105,00 & 105,00 \\
\hline
\end{tabular}

CF (Custo Fixo) - Custo mensal de contratação de um veículo;

NV - Número de veículos

No entanto, como podemos ver na tabela 7 (de forma resumida), a vantagem competitiva da solução do jornal cearense é superior à do Jornal O GLOBO, reduzindo custos operacionais de frota e deslocamento dos veículos, que são os grandes responsáveis pelos custos totais da distribuição e, portanto, refletem o custo final do Jornal.

Porém qual a nossa recomendação, até onde usar o projeto de uma cadeia ou da outra? Observando que o número de rotas dos entregadores foi quase o mesmo para todos os métodos e instâncias, levaremos em consideração somente os custos dos veículos. Os custos do Jornal O POVO se mantiveram em torno de quatro vezes menor para todas as instâncias acima. As instâncias foram construídas para uma área específica, a cidade de Fortaleza, ou seja, a diferença entre elas está na densidade das entregas, as instâncias maiores possuem mais assinantes por metro quadrado. À medida que a densidade aumenta, as distâncias das rotas dos jornaleiros, na estratégia do Jornal o POVO, se aproximam das distâncias das rotas da outra estratégia.

Desta forma, seguindo estes critérios de avaliação, para o caso de Fortaleza, indicamos a solução da rede logística do Jornal O POVO como sendo a de menor custo, não importando o tamanho da instância, ou seja, a quantidade total de entregas diárias.

Os dois Jornais estudados ainda utilizam processos manuais de definição da rede logística. Ambos poderiam diminuir significativamente seus custos se adotassem uma política automática do processo de distribuição. Para o Jornal O GLOBO, onde o volume de entregas é bastante significativo (mais de 170 mil jornais diários), pode-se estimar a melhoria de performance entre 20 e $30 \%$ do custo de distribuição total ao se adotar uma metodologia computacional adequada. O uso de métodos de agregação poderá diminuir o número de jornaleiros necessário para fazer as entregas diárias melhorando também o desempenho de cada um deles, para os dois modelos de distribuição. Portanto, os procedimentos de agrupamento e roteirização combinados se constituem em ferramentas essenciais para a definição da rede logística de distribuição de jornais a assinantes.

\section{Avaliação de Redes de Suprimento para Coleta de Leite a Granel}

O Primeiro Percurso da Coleta de Leite, é feito de forma usual em fazendas e sítios, a partir de uma estação base de recepção. O transporte (no primeiro percurso) representa, na atualidade, entre $4 \%$ a $25 \%$ do preço do leite recebido pelo produtor, chegando, em algumas 
regiões do Brasil, a 40\%, Felício, 1986. Essa diferença é determinada pela baixa densidade de produção, que é a relação da quantidade produzida pela quantidade de quilômetros percorridos pelo veículo, das fazendas às plataformas de recepção, Sobrinho et al., 1995.

O transporte de leite a granel, por sua vez, tem-se mostrado aos países e às firmas que o adotaram como um grande avanço para a pecuária leiteira, pois tem permitido ganhos de qualidade, redução de trabalhos tidos com árduos (horários de ordenha, movimentação dos latões) e uma série de outras vantagens que fazem do sistema a granel superior ao tradicional sistema de coleta a latão.

Em termos históricos, pelo que indica a literatura (Bulk Milk Handling, 1957), o transporte de leite a granel teve seu início nos EUA em 1940 no estado da Califórnia. No Brasil, o sistema de granelização foi introduzido pela CCGL em 1985 e vem expandido-se rapidamente ao longo destes últimos anos. Trata-se de uma prática já consolidada no Brasil hoje, e que vem utilizando recursos computacionais no plano de percursos de forma sempre evidente, da Silva (1998).

Após a crise do petróleo nos anos 70 e a atual crise de 2004, o combustível passou a ter um valor mais expressivo nos custos, logo, é de se esperar uma atenção especial referente à redução de custo por este item, que é representado principalmente pelo primeiro percurso na coleta de leite. O transporte a granel tem um grande potencial na redução dos custos do primeiro percurso, pois permite realizar coleta em dias alternados e, devido a independência de horários é possível racionalizar de forma mais eficiente a linha de coleta.

Dentre os dados pertinentes ao levantamento de custos da coleta do leite, alguns são de relevância, porém não considerados aqui, como, Felício Filho (1986), Sobrinho et al (1995), da Silva (1998):

1. Custo Fixo: valor do veículo novo; valor do pneu novo; valor da câmara; valor da recauchutagem; valor de peças/manutenção/ano; valor da retífica do motor; valor do tanque rodoviário de $6.000 \mathrm{l}$; capacidade do tanque de resfriamento $(500,1000 \mathrm{e}$ 20001); quantidade de pneus/veículo; quantidade de estepes; vida útil do veículo; vida útil do tanque; vida útil pneu novo; vida útil recauchutagem; vida útil retífica; licenciamento e taxas referentes ao veículo; porcentagem sucata do caminhão e do tanque;

2. Custo Variável: salário motorista/dono caminhão; salário do ajudante; preço do combustível (diesel); preço do óleo cárter/litro; preço do óleo câmbio/diferencial/litro; preço da lavagem do veículo; capacidade de óleo cárter; reposição óleo cárter até a próxima troca; capacidade de óleo do diferencial; reposição do óleo diferencial; periodicidade lavagem veículo;

3. Parâmetros: preço pago por quilômetro percorrido; preço pago por litro transportado; quilometragem mensal percorrida e rendimento em quilômetros/litro de combustível consumido. 


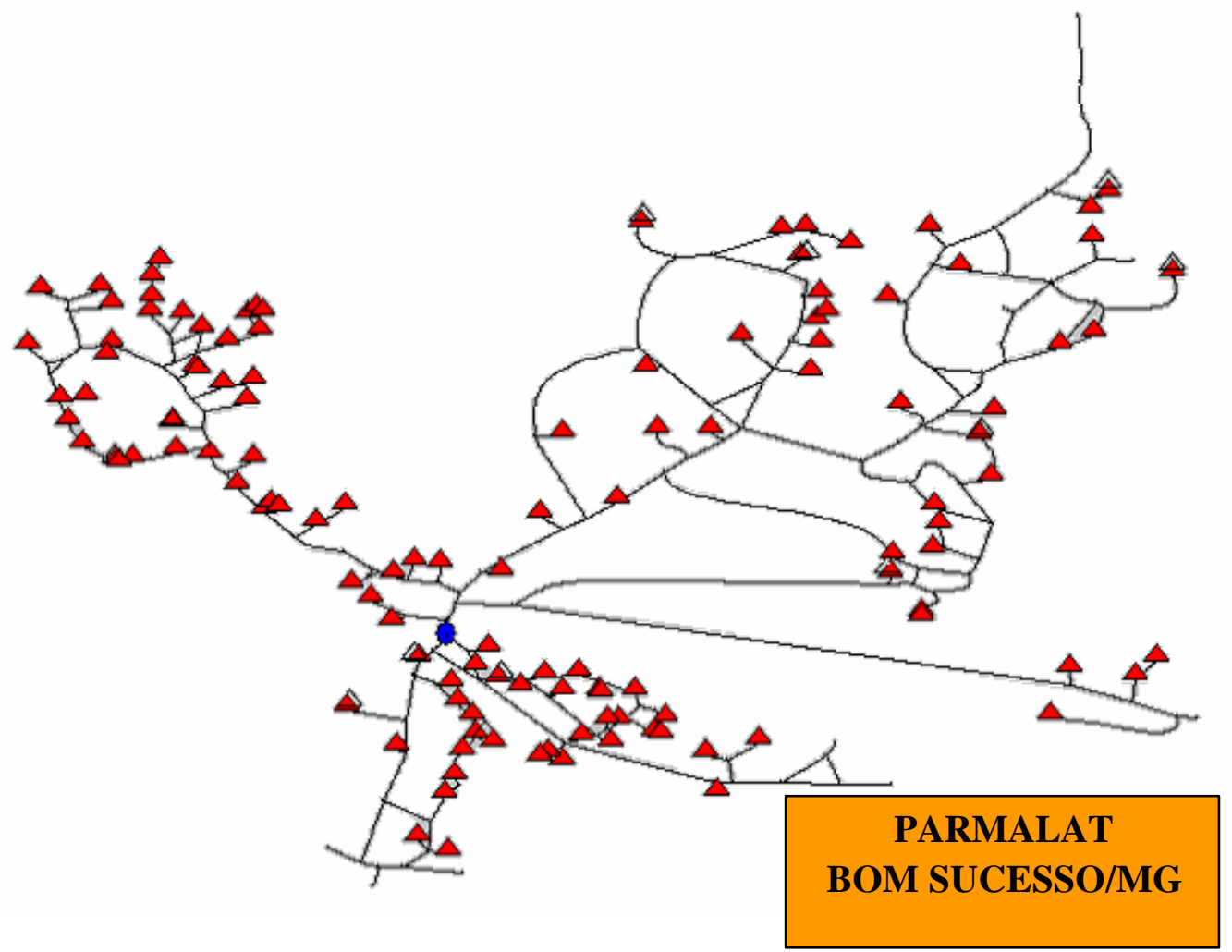

Figura 8: Mapa da bacia leiteira da região de Bom Sucesso - MG

A figura 8 apresenta a bacia leiteira em estudo, cujos dados são reais e obtidos a partir da coleta realizada in loco por da Silva (1998).

A proposta logística para o leite a Granel é a seguinte: os custos da coleta seriam minimizados e a rotatividade aumentada, caso fosse possível concentrar em produtores selecionados tanques de resfriamento (de 1000 ou 20001) os quais atenderiam a uma microbacia leiteira de produtores vizinhos, em dias alternados. O custo aproximado destes reservatórios está em torno de $\mathrm{R} \$ 10 \mathrm{mil}$ e $14 \mathrm{mil}$, respectivamente. Nestes produtores selecionados, seus vizinhos identificados no mesmo grupo iriam dispor seu leite no tanque resfriador, onde o caminhão a Granel com capacidade limitada passaria realizando a coleta. $\mathrm{O}$ investimento destes tanques seria feito pela empresa de coleta, que se ocuparia em atender de forma mais barata os seus fornecedores, que diluiriam assim os custos de transporte aumentando o seu ganho na produção.

Para a Coleta de Leite a Granel, tendo como pressuposto que o leite é resfriado numa propriedade que possui luz elétrica e um tanque de resfriamento o qual pode ser usado por diversos produtores que estão próximos ao centro, o infortúnio de um percurso de um caminhão de leite com tanque de 60001, em geral longo e lento, poderia ser minimizado pois o produto já se encontraria a temperaturas baixas $\left(4\right.$ a $\left.5{ }^{\circ} \mathrm{C}\right)$ podendo ser coletado dia sim dia não. Para o pequeno produtor, o custo do leite se torna atrativo pois não tem que se deslocar muito para disponibilizar o seu leite, assim como aumenta os seus ganhos por litro, pois não incidiria de forma acentuada no seu custo de produção o transporte, este podendo ser feito por tração animal.

No contexto deste procedimento, consideramos então duas alternativas, como nos casos anteriores estudados: Inclusão de apenas um centro de coleta em micro-bacias, e 
inclusão de um centro de coleta por micro-bacias e destes um centro dos centros nas microbacias (10001), com tanques resfriadores maiores (20001), para reduzir drasticamente o percurso da primeira coleta. Estes tanques foram escolhidos por estarem entre os maiores do mercado, e que abrigam uma parcela considerável de leite do caminhão graneleiro.

Após avaliarmos de forma temática os percursos gerados pelas situações com agrupamentos de produtores em micro-bacias em 1000 e 20001 para coleta de leite em dias alternados, ou seja: uma bacia de 5001/dia estoca em dias alternados 10001 e a de 10001/dia estoca 20001. Identificamos que a solução de 10001 com 36 tanques, atende bem ao conceito de proximidade entre pequenos produtores esperado, porém onera substancialmente no custo quanto aos tanques de 10001 à disposição, figura 10.

A solução anterior é pois muito onerosa para a empresa de coleta, se esta é quem investe nos tanques, porém a solução de 10001/dia, com 20 tanques de 20001, figura 12, pode ser utilizada com grande redução no custo fixo ( $22 \%$ do custo com tanque relativo à primeira solução), e 10,5\% do custo do percurso da solução anterior. A figura 9, apresenta uma solução do algoritmo de agrupamento com centro geométrico, Negreiros e Palhano (2004b), considerando tanques de 10001 (ao todo 36 tanques, para 16.5301/dia de leite desta bacia), onde apenas um tanque seria colocado em um produtor específico.

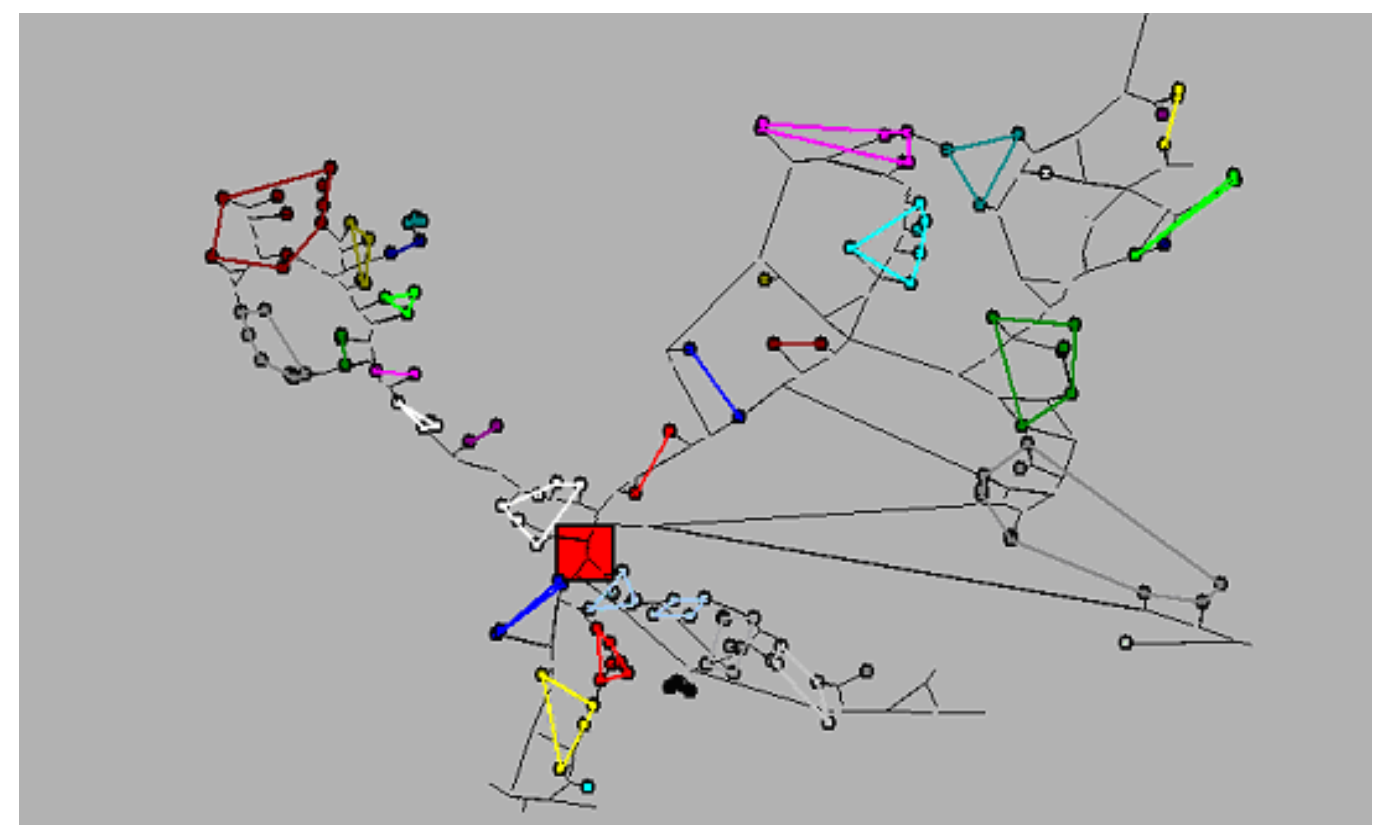

Figura 9: Grupos de clientes (5001/dia) na bacia leiteira (16.5301/dia) de Bom Sucesso-MG 


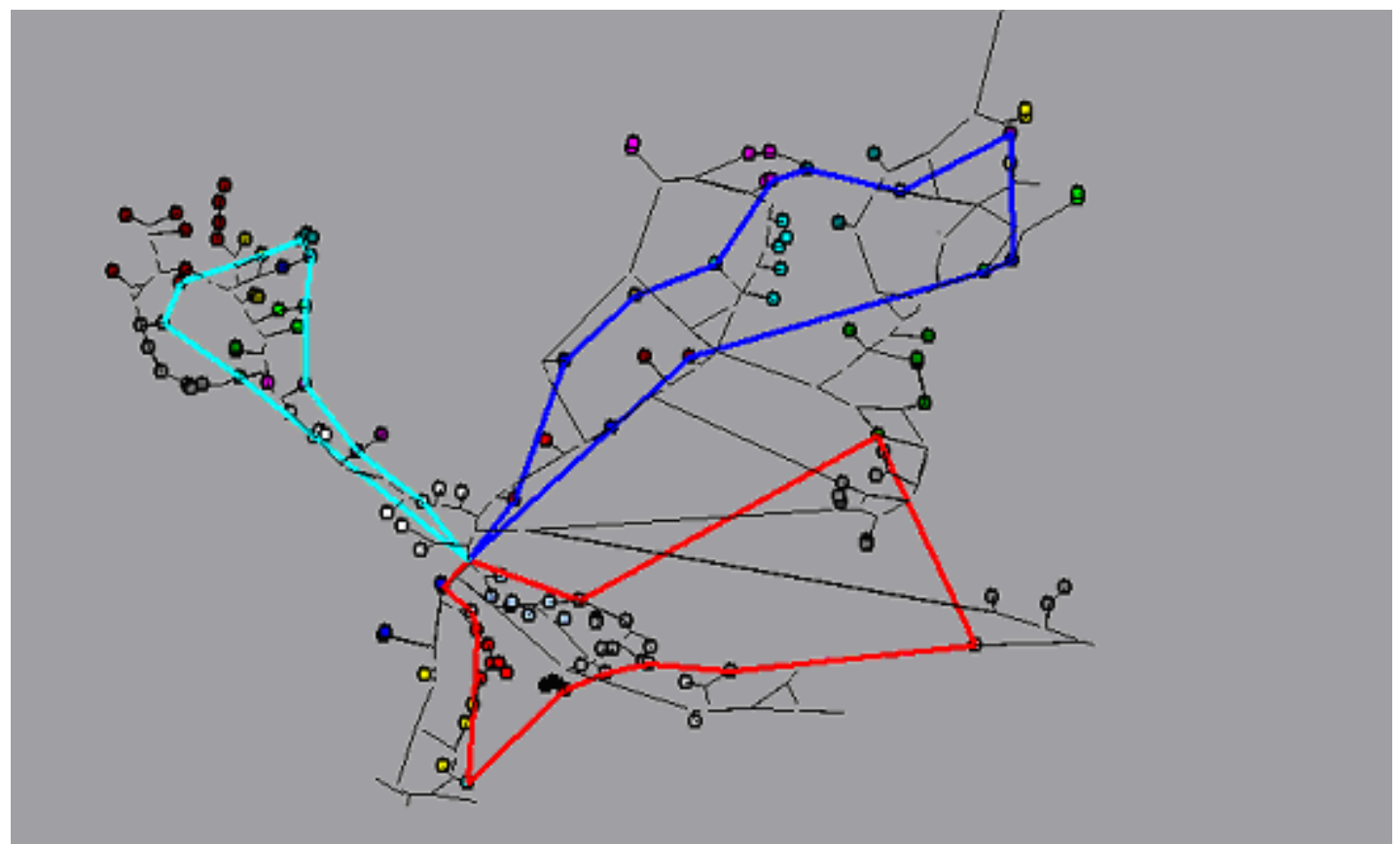

Figura 10: Roteirização do veículo tanque (60001, 3 rotas com Qmax=57001) ), sendo 36 tanques de 10001 nas micro-bacias, e percurso do caminhão graneleiro de 1227 u.c. dia sim dia não.

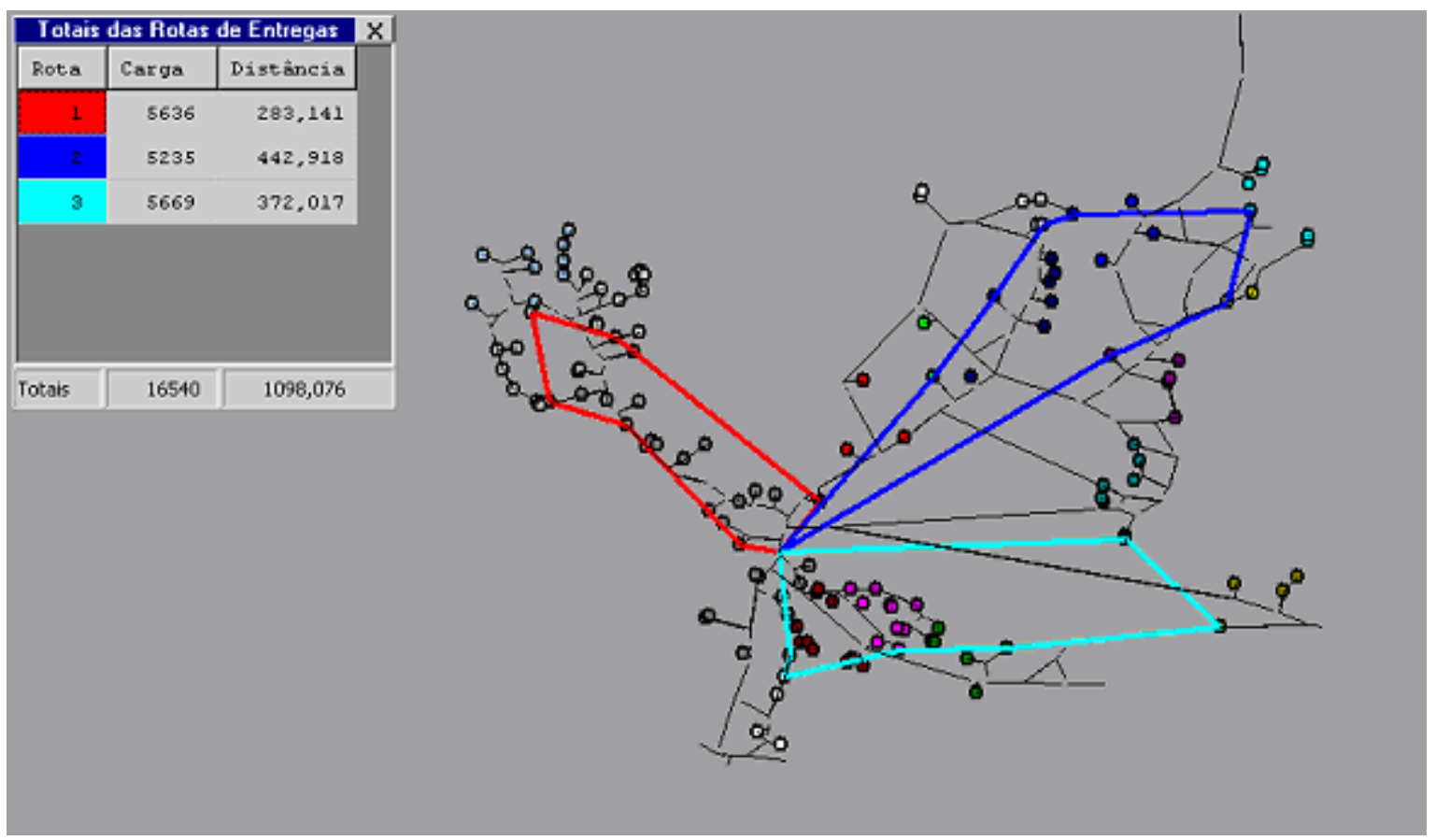

Figura 11: Roteirização do veículo tanque (60001, 3 rotas com Qmax=57001) ), sendo 20 tanques de 20001 nas micro-bacias, e percurso do caminhão graneleiro de 1098u.c. dia sim dia não. 


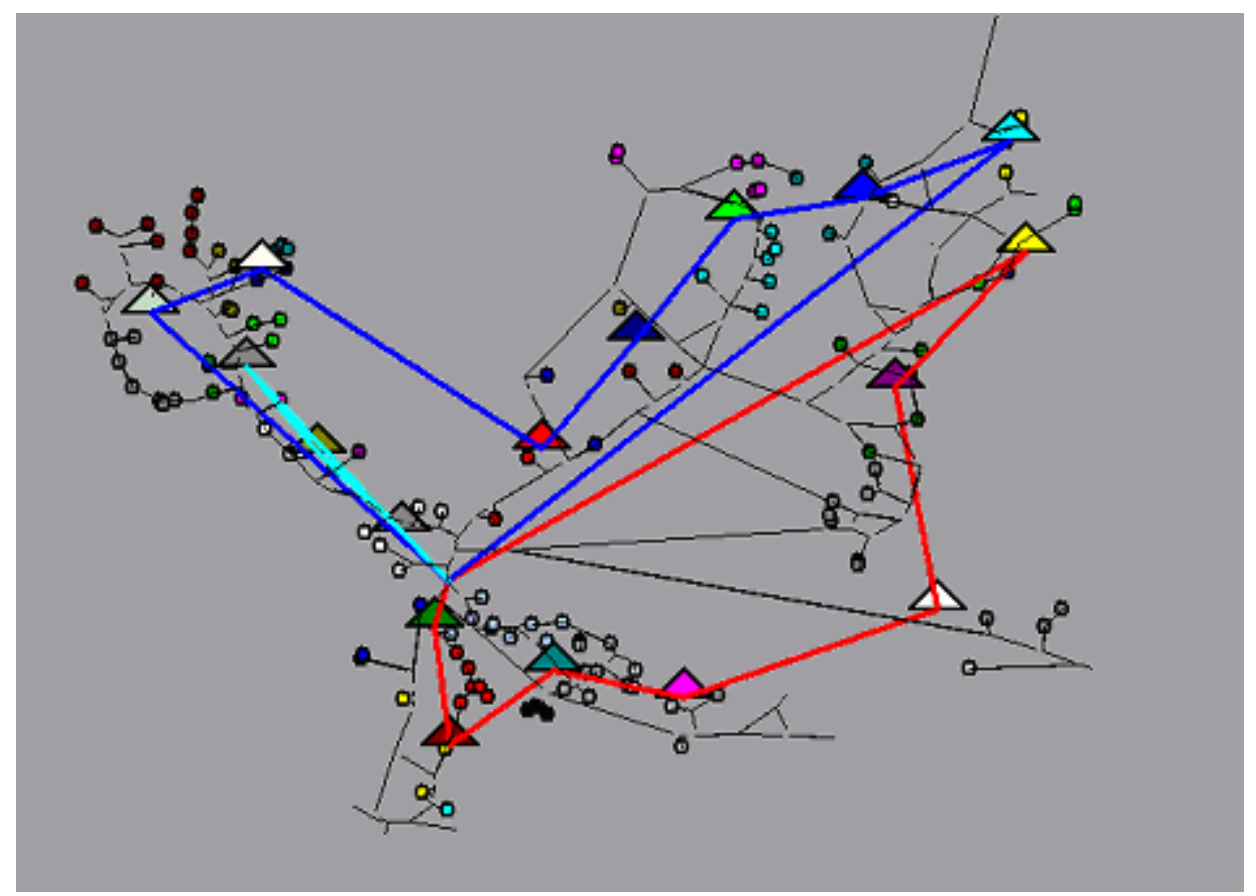

Figura 12: Roteirização do veículo tanque (60001, 3 rotas com Qmax=57001), sendo 17 tanques de 20001 avançados, 36 tanques de 10001 nas micro-bacias, e percurso dos caminhões graneleiros de 1360 u.c. dia sim dia não.

O segundo modelo logístico está apresentado na figura 12. Nela, considerando tanques de 10001 (bacia de 5001/dia), e tanques avançados de 20001, e continuando numa fase inicial com os percursos dos pequenos produtores e numa fase seguinte o produtor eleito por grupo levaria o leite até um tanque resfriador maior de $10001 \mathrm{em}$ um local eqüidistante de todos os produtores das suas micro-bacias agrupadas. O caminhão de coleta (graneleiro) passaria por um conjunto destes tanques (20001), também em três rotas. Esta logística considera dois níveis de agregação como na solução OPOVO, porém dois custos fixos (tanques: $36 \times 10001$ e $17 \times 20001)$ e variáveis (energia e manutenção dos tanques) são inseridos. Notemos que neste caso o custo de quilometragem não reduz o comprimento das 3 rotas, ao contrário, aumenta, tornando proibitiva esta alternativa.

\section{Conclusão}

Este trabalho estudou dois modelos logísticos, via problema de Agrupamento Capacitado com Centro Geométrico e o Problema Generalizado de Percurso de Veículos (Estratégia OGLOBO), e Agrupamento Capacitado em dois níveis com roteirização no nível mais próximo do centro de distribuição (estratégia OPOVO).

Foram consideradas duas situações, na entrega de jornais a assinantes e na coleta de leite a granel, com o objetivo de verificar se sempre uma estratégia supera a outra e seu nível de robustez. Verificamos que cada caso é específico e as estruturas logísticas possuem peculiaridades que estão associadas aos problemas que estão sendo investigados. Entre os jornais, a estratégia do jornal OPOVO mostra-se mais eficiente e menos onerosa, porém está associada ao processo de montagem simultâneo do jornal na central de distribuição (o jornal sai pronto), enquanto na estratégia OGLOBO, pelos jornais não saírem prontos, e as dificuldades locais com relação ao roubo dos pequenos veículos dos entregadores, uma 
logística bem mais dispendiosa pode ser justificada, porém com certo cuidado frente à diferença daquela obtida no jornal OPOVO.

Já na cadeia de primeiro percurso do leite, na coleta de leite a granel, isto se inverte, pois as bases avançadas recebem um custo operacional, porém a própria topologia da rede (parecida com uma árvore, de pouquíssima densidade) ajuda na confecção de percursos próximos ao ideal, baixando sobremaneira em relação ao percurso produtor a produtor hoje praticado. A solução do PGPV é pois mais adequada, desde que os tanques das micro-regiões possam se configurar numa realidade aceitável pelos pequenos produtores haja vista a distância que precisam percorrer para deixar o seu leite diariamente.

Foi utilizada neste trabalho a ferramenta computacional de roteirização $\underline{\text { SisRot }}$ News, desenvolvida no Brasil pela GRAPHVS, e que implementa de forma integrada estes conceitos que aqui foram estudados.

\section{Bibliografia}

Beasley, J. (1983) Route-First Cluster Second Methods for Vehicle Routing, Omega, vol 11, pp. $403-408$

Bodin, L., Golden, B.L., Assad, A.A., Ball, M (1983) Routing and Schedulling of Vehicles and Crews: The State of the art. Computers and Operations Research vol 10.

Bulk Milk Handling (1957) Michigan: Michigan State University, 132p.

Da Silva, I.C.V. (1998) 'Custo e Otimização de Rotas no Transporte de Leite a Latão e a Granel: Um Estudo de Caso", UFLA, Adminstração Rural, Dissertação de Mestrado

Felício Filho, A. (1986) "Custo e Sistema de Transporte do Primeiro Percurso do Leite", Informe Agruopecuário, Belo Horizonte, no. 12(137)/Maio, pgs. 14-16

Gillett, B.E. and Miller, LR (1974) "A Heuristic Algorithm for the Vehicle Routing Problem”, Operations Research vol. 22, pgs. 240-349.

Hansen, P., Mladenovic,N. (2000) 'Variable Neighborhood Search: A Chapter of handbook of Applied Optimisation”, Les Cashiers du GERAD G-2000-03

Laporte, G., 1988. Location-routing problems. In: Golden, B.L., Assad, A.A. (Eds.), Vehicle Routing: Methods and Studies. North-Holland, Amsterdam, pp. 163 \pm 197.

Negreiros Gomes, M.J , Palhano, A.W.C (2004a) "The Capacitated Centred Clustering Problem", Comp. \& Op. Res. (to appear)

Negreiros Gomes, M.J , Palhano, A.W.C (2004b) "New Algorithms for the Generalized Vehicle Routing Problem", Optimisation Days, Montreal/CA

Palhano, A.W.C (2004) "Novos Métodos de Agrupamento Capacitado e Roteamento Generalizado Aplicados na Distribuição de Jornais a Assinantes", Dissertação de Mestrado, MPCOMP-UECE/CEFET-CE, Fortaleza/CE 
Sanchi-Levi, D. Kaminsky, P., Simchi-Levi, E. (2003) Cadeia de Suprimentos, Projeto e Gestão (Conceitos, Estratégias e Estudos de Casos), Ed Bookman

Sobrinho, F.F.; Coutinho, G.H. e Coura, J.D. Coleta de leite a granel. Belo Horizonte: Fundação João Pinheiro, 1995. 96p. (Monografia) 